\title{
PHYTO-MEDIATED GREEN SYNTHESIS OF COPPER NANOPARTICLES: STUDY OF CATALYTIC PERFORMANCE AND ANTIBACTERIAL ACTIVITY
}

\author{
M. Reddeppa ${ }^{1}$, P. Srujana ${ }^{1}$, R. Chenna Krishna Reddy ${ }^{2,4}$, T. Veera Reddy ${ }^{3}$ \\ and T. Shobha Rani ${ }^{1 *}$ \\ ${ }^{1}$ Department of Chemistry, Dravidian University, Kuppam-517425, India \\ ${ }^{2}$ Department of Chemistry, South China Normal University, Guangzhou, P.R. China \\ ${ }^{3}$ Department of Chemistry, VikramaSimhapuri University, Nellore-524320, AP.India \\ ${ }^{4}$ Department of Science \& Humanities, S.V.College of Engineering, Karakambadi Road, \\ Tirupati-517507, India \\ *E-mail: sobha.kaushu@gmail.com
}

\begin{abstract}
The present study represents the phyto-mediated green synthesis approach of Copper Nanoparticles (CuNps) by using Nelumbo nucifera seed extract, as the method of synthesis is simple eco-friendly without using any hazardous chemicals. The seed extract of Nelumbo nucifera acts as both reducing and capping agents for producing CuNps with mixed fine cubic and spinel morphology. The results of the structural analysis performed with the help of UVvisible spectroscopy (an absorption peak at around $535 \mathrm{~nm}$ ) and X-ray diffraction (crystalline nature) confirmed the successful formation of copper nanoparticles. Also, the FT-IR spectrum evidenced that the synthesized CuNps were protected and stabilized by bio-molecules with different functional groups present in seed extract. The shape of the synthesized CuNps is cubic and spinel with 60-80 nm size range from scanning electron microscope results and the presence of elemental copper is further confirmed by energy dispersive spectroscopy analysis. Finally, the CuNps exhibited reliable antibacterial activity on Staphylococcus aureus (Gram-positive), Bacillus subtilis (Gram-positive), Pseudomonas aeruginosa (Gram-negative) and Escherichia coli (Gram-negative), and excellent catalytic activity towards Huisgen [3+2] cycloaddition reaction.

Keywords: Phyto-mediated Green Synthesis, Nelumbo nucifera, Copper Nanoparticles, Catalytic Performance, Antibacterial Activity.
\end{abstract}

(C) RASĀYAN. All rights reserved

\section{INTRODUCTION}

Nanotechnology is a fast-growing branch of science for producing and utilizing nano-sized particles for various applications in different fields. In recent days, the synthesis of metal nanoparticles by various synthetic protocols is the most effective research area in the modern material science as it exhibits exceptional properties like optical, electrical, catalytic, biosensing, therapeutic etc., owing to their small size, high surface area, uniform distribution and their distinct morphology. ${ }^{1-3}$ Various physicochemical methods were employed for producing metal nanoparticles such as silver, copper, gold, platinum, etc. ${ }^{4-7}$ Mostly, using such methods for nanoparticle preparation contains the involvement of toxic chemicals, the use of high temperature, pressure, and low material conversions. To avoid the usage of harmful chemicals and hectic reaction conditions, there is increasing attention for developing new, eco-friendly processes for nanoparticle synthesis.

Further, it is well known from the early days, that copper is used for many purposes mainly in the sterilization of water and wounds. It is approved for the treatment of pulmonary diseases and purification of water by ancient Greeks (400 BC). People have used copper made utensils for cooking to avoid the spreading of diseases. Copper is a constituent of many enzymes involved in several body functions that are essential to human health. Given important applications in various fields, copper nanoparticles (CuNps) were synthesized by adapting several methods and these methods involved in the usage of

Rasayan J. Chem., 13(3), 1885-1893(2020)

http://dx.doi.org/10.31788/ RJC.2020.1335830

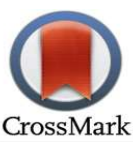


RASĀYAN J. Chem.

Vol. 13 | No. 3 |1885-1893| July - September | 2020

expensive, toxic and/or hazardous chemicals and harmful organic solvents. ${ }^{8-9}$ The approach involved the occurrence of toxic and/or hazardous materials on the surface of the nanoparticles makes them less viable and was prone to accumulate many environmental issues.

Hence, to address such issues, the fabrication of nanomaterials with biocompatible reductants of living organisms is one of the effective approaches in nanoscience and technology. ${ }^{10-12}$ In addition to this, the biosynthesis method involves plant extracts as biocompatible reductants have come out with a simple, ecological and possible substitute to physical and chemical processes. Fabrication of CuNps by aqueous extracts derived from various plants is an environmentally affable, inexpensive profitable procedure without the use of dangerous chemicals. Advantageously, the effort-less reaction setup, ambient reaction conditions and the use of water like green solvents during the synthesis offered rich bio-potent applications in pharmaceutical and bio-medical fields. ${ }^{13-14}$

Owing to have a wide surface to volume ratio and remarkably tiny in size, recently copper nanoparticles play a prominent role in various scientific fields and can also serve as antifungal or antibacterial agents. The antimicrobial activity of CuNps is due to their close interaction with microbial membranes and the release of metal ions in solutions. ${ }^{15-16}$ Also, metal nanoparticles of silver, copper, and gold, etc. exhibit catalytic performance in different organic protocols due to the presence of large surface area and these catalysts can be easily separated from reaction mixtures and the catalyst is easily recyclable. ${ }^{17-18}$

Nelumbo nucifera belongs to the Nelumbonaceae family called as Indian lotus. This water plant also has other names like bean of India, sacred lotus and/or simply lotus. Nelumbo nucifera is one of the recurrent water plants growing at the bottom of the ponds and lakes. It has large leaves that float on the water surface. This Indian national plant can be capable to survive/develop in different water body conditions and even in moderate sunlight. It is used as a natural purifier in treatment of wastewater bodies for removing various man-made and/or industrially discharged pollutants and heavy metals, mainly the leaves decreases the growth of algae in the water that arrests eutrophication. ${ }^{19}$ From the literature, it is clear that all parts of Nelumbo nucifera are non-poisonous and the pharmacological studies of the plant revealed that entire parts of the plant possess medicinal value, out of which rhizomes are the main utilization parts in addition to the seeds. Usually, the big leaves, rhizomes and seeds in the form of traditional medicines have been used in Ayurveda and oriental medicine, particularly the leaves are used for the treatment of blood vomiting, nose bleeding (called as epistaxis) and presence of red blood cells in urine (called as hematuria).

The spherical or oval shape of lotus seeds contains a high amount of nutrients, proteins and huge levels of essential amino acids in the form of albumin/globulin (Fig.-1). The hydroalcoholic seed extract of Nelumbo nucifera exhibits anti-oxidant properties because it contains phytochemicals, for example, alkaloids, polyphenolics and carbohydrates etc. ${ }^{20}$ Many researchers reported that the lotus seeds also contain flavonoids, alkaloids, vitamins, carbohydrates, calcium, zinc, and iron. These functional compounds can be used for curing diseases such as digestion problems, diarrhea, cancer, fever and heart complaints. What's more, the flowers and rhizomes are also used in the treatment of diarrhea, cholera, hyperdipsia, diuretic, diabetic and inflammatory problems. ${ }^{21-23}$
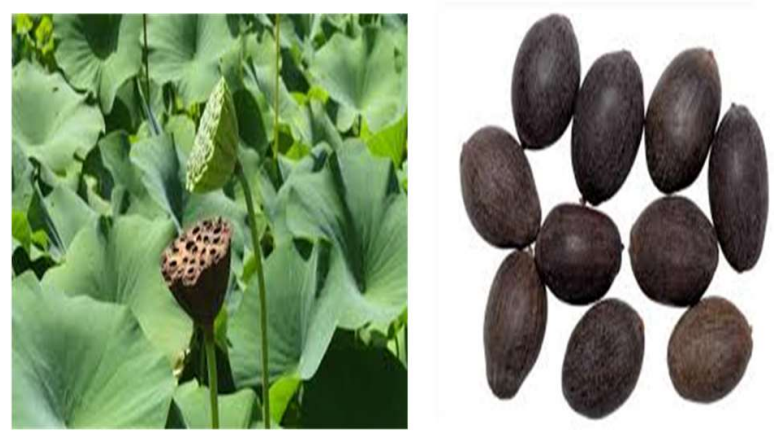

Fig.-1: Seed head of Nelumbo nucifera and their seeds 
RASĀYAN J. Chem.

Vol. 13 | No. 3 |1885-1893| July - September | 2020

Tetrazoles are nitrogen-based five-membered heterocyclic compounds, studied broadly owing to their ample biological and commercial applications and have received much focus due to their utility in drug design and development as an isosteric substitute for carboxylic acids. ${ }^{24,25}$ Synthesis of the tetrazole ring and its derivatives is a key step in medicinal and synthetic organic chemistry research. In the literature survey, a variety of methods were used for the synthesis of tetrazoles that were well recognized and 5substituted ${ }^{1} H$-tetrazoles were prepared with the aid of various substrates through [3+2] cycloaddition reaction using green catalysts. ${ }^{26}$ Moreover, to abate the environmental pollution issues, the researchers focusing on the synthesis of more challenging products, which shows a renewable and sustainable property. These are bio-degradable and having negligible environmental problems, exhibit low animal or human health risks and safety problems. ${ }^{27}$ To overcome the environmental issues, there is an urgent need in the development of alternate and low expensive fuels, minimizing the harmful by-products and wastes at the time of synthesis. For all these issues green catalysts are required to carry out the above processes. ${ }^{28-31}$ Attempts were made successfully for preparing basic derivatives of tetrazoles using CuNps as a catalyst with the use of primary amines, triethyl orthoformate and sodium trinitride. In the presence of CuNps as a catalyst, the reaction was carried out at low reaction time, without using solvent conditions. In this reaction,CuNps acts as Lewis acid to promote the formation of 1 -substituted ${ }^{1} H-1,2,3,4$ tetrazoles. $^{32}$

The present study was focused on an easy, safe and green synthesis approach to construct CuNps using seed extract of Nelumbo nucifera which acts as both reductant and stabilizing agent. Thereafter the characterization techniques such as UV-Visible, FT-IR, XRD, SEM and EDX were employed to confirm the formation of CuNps. After successful fabrication with the above seed extract, these copper nanoparticles were studied for their biological activity against various bacterial strains and catalytic performance for green synthesis of 5 -substituted ${ }^{1} H$-tetrazoles.

\section{EXPERIMENTAL}

All chemicals and solvents used for synthesis, biological and catalytic study were commercially available, analytical grade and were used as such without purification. Bruker Alpha FT-IR spectrophotometer was used to record IR spectra and Bruker $400 \mathrm{MHz}$ NMR spectrometer operating at $400 \mathrm{MHz}$ in DMSO-d6 (TMS as an internal standard) was used to record ${ }^{1} \mathrm{H}$ NMR spectra. Similarly, LC-MS Shimadzu, Japan, positive $(+)$ mode and Thermo Finnegan Instrument were used to record mass spectra and elemental analyses, respectively.

\section{Preparation of Seed extract of Nelumbo nucifera}

The seeds of Nelumbo nucifera were accumulated from the locality of Punganur, Chittoor district, Andhra Pradesh, India. The collected seeds were cleansed with ordinary water initially and later with distilled water to purge impurities and subjected for drying at ambient temperature. After that, the seeds were ground into small pieces and powdered via mortar and pestle. In a $250 \mathrm{~mL}$ round-bottomed flask, $10 \mathrm{~g}$ of dried seed powder was combined with double-distilled water $(100 \mathrm{~mL})$. It was introduced for reflux at 70 $80^{\circ} \mathrm{C}$ for thirty minutes under heating magnetic stirrer. Later on, the seed extract was collected upon centrifugation at $7000 \mathrm{rpm}$ and filtration by using Whatman no.1 filter paper. The collected filtrate was stored at the refrigerator.

\section{Preparation of Copper Nanoparticles}

The CuNps were fabricated according to the method discussed in the literature., ${ }^{2,17,18}$ Typically, $25 \mathrm{~mL}$ of $\mathrm{CuCl}_{2} \cdot 2 \mathrm{H}_{2} \mathrm{O}(5 \mathrm{mM})$ solution was thoroughly mixed with $75 \mathrm{ml}$ of seed extract in $250 \mathrm{~mL}$ Erylen Mayer flask. The above reaction mixture was constantly stirred for sixty minutes at ambient temperature with a magnetic stirrer. The color of reaction mixture changes from hazy appearance to dark brown suggests the copper nanoparticles' formation (Fig.-2). The reaction mixture was covered with silver foil and kept under incubation for 2days. The development of copper nanoparticles formation was examined using spectral data obtained from UV-visible spectroscopy and FT-IR instruments. Then, the reaction mixture was centrifuged at $7000 \mathrm{rpm}$, filtered and then dried in a hot air oven. In the end, a fine powder of copper nanoparticles was obtained. SEM and EDS were also studied for structural confirmation of their formation. 
RASĀYAN J. Chem.

Vol. 13 | No. 3 |1885-1893| July - September | 2020
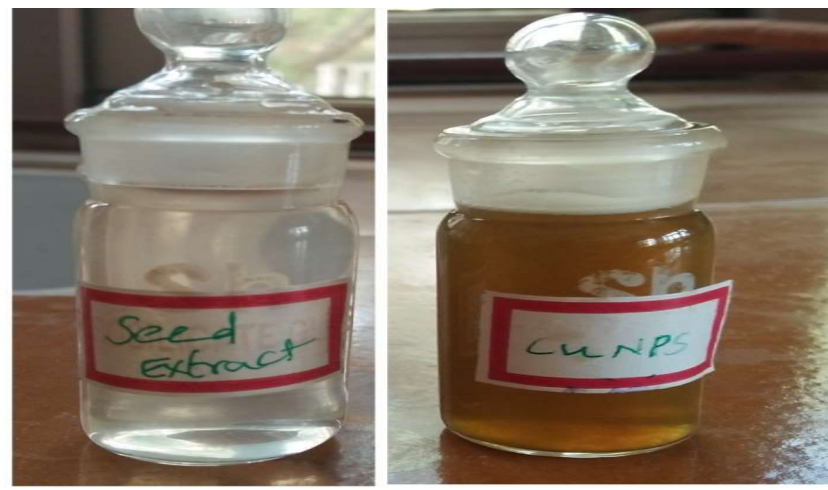

Fig.-2: Green Synthesis of Copper Nanoparticles, Seed extract and as formed CuNps

\section{Preparation of 5- (4-Nitrophenyl) $-{ }^{-1} H$-tetrazole}

The substrates, 4-nitrobenzonitrile $(1 \mathrm{mmol})$, sodium trinitride $(1.5 \mathrm{mmol})$ and the catalyst, CuNps $(15 \mathrm{~mol} \%)$ were solubilized in $5 \mathrm{ml}$ of glycerol in a round-bottomed flask and then reflux the reaction mixture at $110{ }^{\circ} \mathrm{C}$ for 120 minutes. Periodically, the reaction progress was monitored with the help of TLC. The disappearance of reactants indicates the completion of cycloaddition reaction, and then the reaction crude was treated with $10 \mathrm{ml}$ of $0.1 \mathrm{~N}$ muriatic acid to adjust its $\mathrm{pH}$ followed by extraction into ethyl acetate. Finally the light yellow colored $5-\left(4-\right.$ Nitrophenyl) ${ }^{-1} H$-tetrazole was collected after a few water washings and concentrated under reduced pressure (Scheme-1).

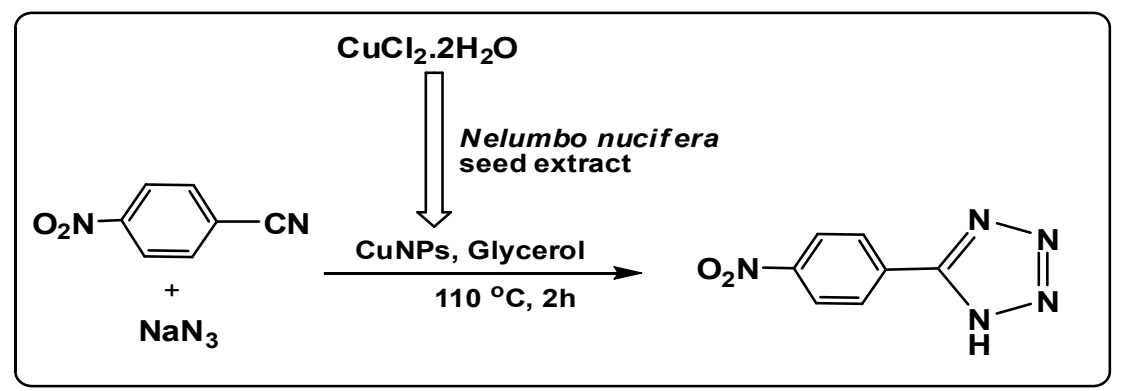

\section{Antibacterial Assay}

Scheme-1: CuNps Catalyzed Synthesis of 5-(4-Nitrophenyl)- ${ }^{1} H$-tetrazole

The synthesized copper nanoparticles from Nelumbo nucifera seed extract was examined for antibacterial activity by using the agar well diffusion method with slight modifications. ${ }^{33-36}$ The CuNps were used to test its antibacterial activity against Staphylococcus aureus (Gram-positive), Bacillus subtilis (Grampositive), Pseudomonas aeruginosa (Gram-negative), and Escherichia coli (Gram-negative). Initially, the seeded agar medium was carefully prepared using Muller Hilton under aseptic environment and allowed to cool and then add $0.1 \mathrm{~mL}$ of diluted inoculum $\left(10^{6} \mathrm{cfu} / \mathrm{mL}\right)$ of bacterial strains just before solidification of broth. It was then transferred into sterilized petri plates under sterile conditions. After that, cork borer was used to make wells of $6 \mathrm{~mm}$ diameter which is free from contamination caused by microorganisms. The CuNps solution samples of $10 \mu \mathrm{L}, 20 \mu \mathrm{L}, 30 \mu \mathrm{L}$, and $40 \mu \mathrm{L}$ were poured into wells on all petri plates in association with DMSO solvent as a negative control. Finally, the cell-cultured dishes were incubated at $40 \pm 5{ }^{\circ} \mathrm{C}$ for $24 \mathrm{~h}$. The zone of inhibition (in $\mathrm{mm}$ ) was measured and the results were compared with the standard drug benzylpenicillin (positive control at the concentration of $20 \mu \mathrm{g} / \mathrm{mL}$ ).

\section{RESULTS AND DISCUSSION}

In this paper, we have discussed the green synthesis method for the construction of CuNps by using Nelumbo nucifera seed extract. Also, the antibacterial profile of CuNps was investigated against four bacterial strains and the catalytic performance was studied for the synthesis of tetrazole derivative. 
RASĀYAN J. Chem.

Vol. 13 | No. 3 |1885-1893| July - September | 2020

\section{Characterization of CuNps}

The biosynthesized copper nanoparticles from Nelumbo nucifera seed extract were studied using UVvisible spectroscopy in the wavelength range of $200-800 \mathrm{~nm}$. FT-IR spectrum was recorded in the range of $4000-400 \mathrm{~cm}^{-1}$ at a resolution of $4 \mathrm{~cm}^{-1}$. This technique was helpful to identify the functional groups responsible for $\mathrm{CuNps}$ preparation as capping and stabilizing agents. XRD analysis was used to recognize the crystalline structure of CuNps. The surface morphology of CuNps and their average particle size was measured using Scanning Electron Microscopy (SEM). In addition to this Energy Dispersive Spectroscopy (EDS) was used for elemental analysis present in the sample.

\section{UV-visible Analysis}

According to the UV-visible spectral data, a distinctive absorption peak was recorded at $535 \mathrm{~nm}$, confirms the formation of copper nanoparticles. There was not observed such peak at that wavelength for plain seed extract ${ }^{37}$. The typical UV-visible spectrum as depicted in (Fig.-3).

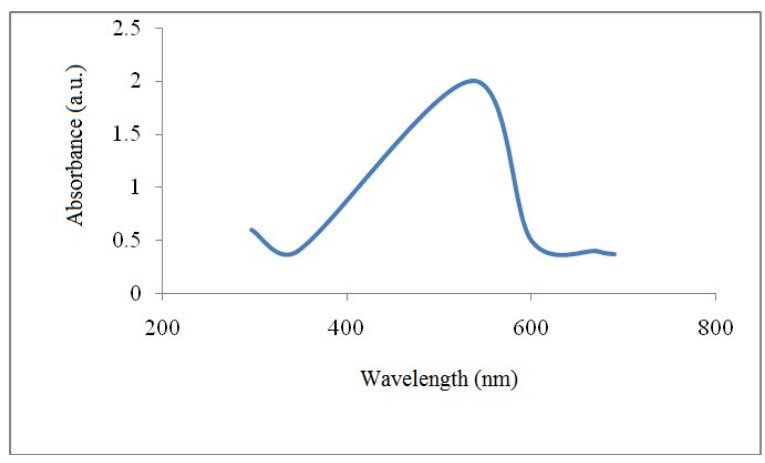

Fig.-3: UV- visible Spectrum of Copper Nanoparticles

\section{X-Ray Powder Diffraction Analysis}

The shape of synthesized nanoparticles was also confirmed by XRD results (Fig.-4) which exhibited three peaks at around 43.45 (111), 51.05 (200) and 75.50 (220) proved the cubic crystalline structure of CuNps. The crystallite size was $\sim 81.23 \mathrm{~nm}$ calculated according to the Scherrer equation. Further, the diffraction values were much close to the JCPDS card no.72-0140.

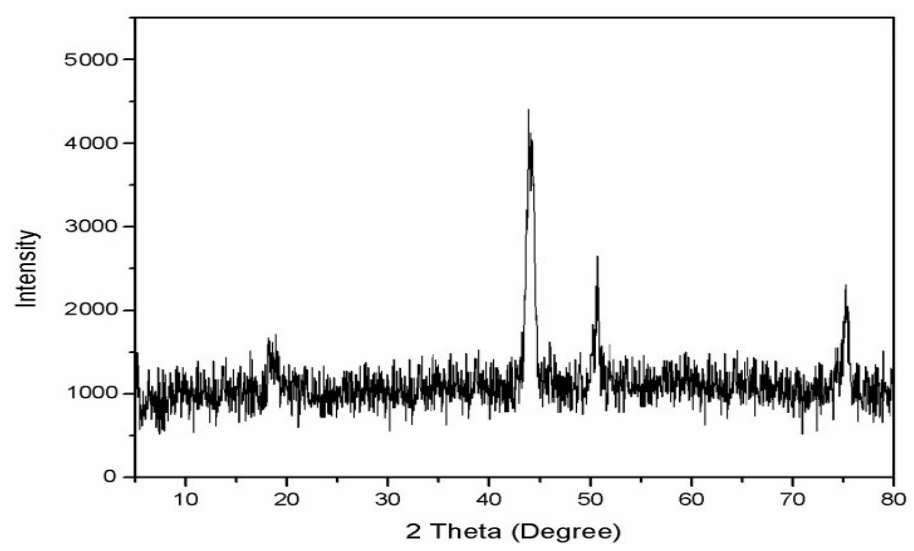

\section{Fourier Transform Infrared (FTIR) Analysis}

Fig.-4: XRD Spectrum of Copper Nanoparticles

The FT-IR analysis of copper nanoparticles prepared from seed extract was carried out for the identification of biocompatible reductants that was responsible for the formation of copper nanoparticles. The obtained results were correlated to recognize the bio-molecules accountable for the formation of CuNps and also acts as stabilization and capping agents. In our examination, the major peaks have 
RASĀYAN J. Chem.

Vol. 13 | No. 3 |1885-1893| July - September | 2020

observed at $3334 \mathrm{~cm}^{-1}, 3444 \mathrm{~cm}^{-1}(\mathrm{O}-\mathrm{H}$ and N-H stretching frequencies of H-bonded alcohols, phenols and amino acids), $1635 \mathrm{~cm}^{-1}$ (C=O stretching), $1408 \mathrm{~cm}^{-1}$ (O-H deformation), $2193 \mathrm{~cm}^{-1}$ to $2114 \mathrm{~cm}^{-1}$ due to (C-H stretching) and $1068 \mathrm{~cm}^{-1}$ to $847 \mathrm{~cm}^{-1}$ (symmetric stretching of carboxylate group) mainly occurs due to stretching of carbonyl moiety in the amide linkages of the protein. All this data ascribed to the presence of functional groups like hydroxyl and carboxylic acids, as their original form again attributed to the participation of fatty acids, proteins, and flavanoids in the formation and stabilization of $\mathrm{CuNps}^{38}$. Hence, it is evident that the phytochemicals present in Nelumbo nucifera seed extract are responsible for the formation of CuNps and the typical FT-IR spectrum was shown in Fig.-5.

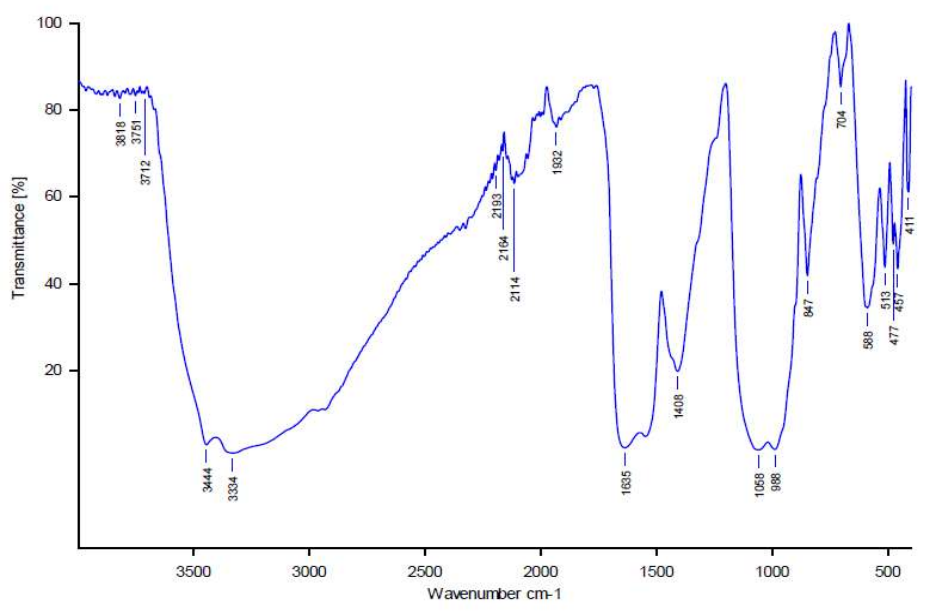

Fig.-5: FTIR Spectrum of Copper Nanoparticles

\section{Scanning Electron Microscope (SEM) and Energy Dispersive X-Ray Spectroscopy (EDX or EDS) Analysis}

The successful formation of CuNps was further confirmed by SEM-EDX analysis and the nanoparticles appeared to be mixed cubic and spinel morphological structures which were shown in (Fig.-6). Further, it was confirmed from EDX analysis that, the test sample exhibited distinct characteristic peaks for the presence of different elements along with their weight percentages. The elements carbon, oxygen, chlorine, and copper were observed with their weight percentages of $33.20,35.63,10.58$, and $20.59 \%$ respectively. This data indirectly suggests the presence of the maximum percentage of organic content due to the presence of strong signals corresponding to the $\mathrm{C}, \mathrm{O}$ and $\mathrm{Cl}$, when compared to the inorganic content i.e., metallic copper nanoparticles..$^{39,40}$

\section{Catalytic Activity}

From the literature, it is clear that copper-catalyzed 1,3-dipolar cycloadditions have appeared as a potent tool in the development of heterocyclic chemistry. Motivated from our previous work, here also we tested the catalytic activity of green synthesized copper nanoparticles in cycloaddition reaction ${ }^{18}$. As expected, the CuNps exhibited excellent catalytic activity when they were used as a catalyst in the preparation of 5(4-Nitrophenyl)- ${ }^{1} H$-tetrazole with good yields. Again, it is proved that the synthesis method is benefitted from the green solvent system, reutilization of catalyst, less time reaction with good yields. The spectral data for the synthesized compound was depicted as below. Color: light yellow, yield: 80\%, m.p.: 78-80 ${ }^{\circ} \mathrm{C}, ;{ }^{1} \mathrm{H}$ NMR (400 MHz, DMSO- $\left.d_{6}, \delta, \mathrm{ppm}\right): 8.15$ (d, $\left.J=7.20 \mathrm{~Hz}, 2 \mathrm{H}, \mathrm{Ar}-\mathrm{H}\right), 7.45(\mathrm{~d}, 2 \mathrm{H}, J=7.3 \mathrm{~Hz}$, $\mathrm{Ar}-\mathrm{H}$ ), 3.68 (br s, $1 \mathrm{H}, \mathrm{NH}$, overlap with solvent), LC-MS (positive, $m / z(\%)$ ): $206[\mathrm{M}+\mathrm{H}]^{+}(100)$; Anal. Calcd. For $\mathrm{C}_{8} \mathrm{H}_{7} \mathrm{~N}_{5} \mathrm{O}_{2}$ : C, 46.83; H, 3.44; N, 34.13. Found: C, 47.22; H, 3.71; N, 34.76\%.

\section{Antibacterial Activity Study}

According to the literature, it is well known from ancient times that, metallic copper was used to sterilizing water, wounds and it is a constituent of many enzymes involved in several body functions that are essential to human health. It is also found in hair, elastic tissue enclosed in skin, bone and other 
RASĀYAN J. Chem.

Vol. 13 | No. 3 |1885-1893| July - September | 2020

organs ${ }^{13-14}$. Also, from the FT-IR study, it is evident that several biomolecules adhered to the copper nanoparticles make them bio-potent. As mentioned earlier in the experimental section, the antibacterial assay of copper nanoparticles fabricated with seed extract of Nelumbo nucifera was examined by agar well diffusion method ${ }^{33-36}$.

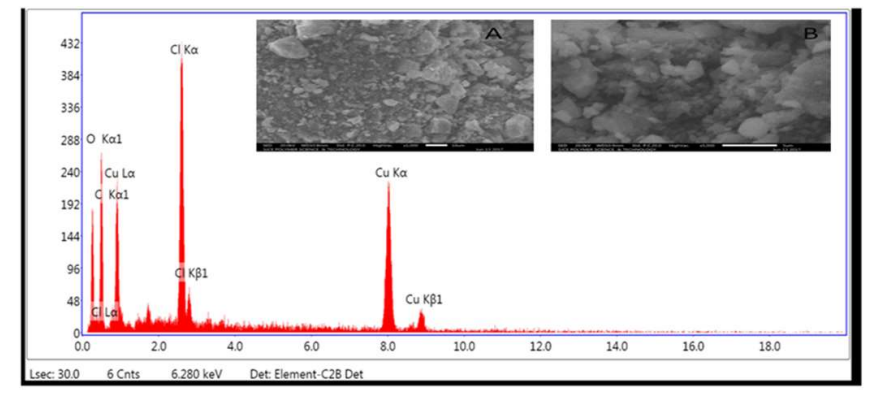

eZAF Smart Quant Results

\begin{tabular}{|cccccc|}
\hline Element & Weight \% & Atomic \% & Net Int. & Error \% & Kratio \\
\hline CK & 33.20 & 49.24 & 34.45 & 13.01 & 0.0710 \\
\hline OK & 35.63 & 39.67 & 61.91 & 12.06 & 0.0583 \\
\hline CIK & 10.58 & 5.32 & 139.96 & 4.47 & 0.0807 \\
\hline CuK & 20.59 & 5.77 & 108.65 & 3.94 & 0.1804 \\
\hline
\end{tabular}

Fig.-6: SEM-EDX Spectrum of Copper Nanoparticles

After analyzing the test results, the bio-potent CuNps have performed best action at the concentration 40 $\mu \mathrm{g} / \mathrm{mL}$ against all the cell cultures such as Staphylococcus aureus (Gram-positive), Bacillus subtilis (Gram-positive), Pseudomonas aeruginosa (Gram-negative), and Escherichia coli (Gram-negative). The zone of inhibition (Table-1) was calculated $(\mathrm{mm})$ and the results were compared with standard drug benzylpenicillin. Excellent sensitivity was observed for Escherichia coli and Bacillus subtilis with a zone of inhibitions $18 \pm 1.4 \mathrm{~mm}$ and $17 \pm 1.3 \mathrm{~mm}$, respectively when compared to Staphylococcus aureaus (15 $\pm 0.4 \mathrm{~mm})$ and Pseudomonas aeruginosa $(14 \pm 1.4 \mathrm{~mm})$. It was worth mentioning that the antibacterial profile of CuNps is concentration/dose dependant and performed well against all the tested Gram-positive and Gram-negative bacterial strains.

Table-1: Antibacterial Activity of Green Synthesized Copper Nanoparticles

\begin{tabular}{c|c|c|c|c|c}
\hline S.No. & $\begin{array}{c}\text { CuNps } \\
(\mu \mathrm{g} / \mathrm{mL})\end{array}$ & S. aureus & B. subtilis & P. aeruginosa & E. coli \\
\hline 1 & 10 & $10 \pm 1.5$ & $10 \pm 0.6$ & $09 \pm 1.0$ & $11 \pm 0.6$ \\
\hline 2 & 20 & $11 \pm 0.3$ & $11 \pm 1.4$ & $10 \pm 1.2$ & $12 \pm 0.5$ \\
\hline 3 & 30 & $11 \pm 0.5$ & $13 \pm 1.2$ & $12 \pm 0.8$ & $13 \pm 1.6$ \\
\hline 4 & 40 & $15 \pm 0.4$ & $17 \pm 1.3$ & $14 \pm 1.4$ & $18 \pm 1.4$ \\
\hline 5 & Std $^{*}$ & $24 \pm 1.5$ & $23 \pm 0.5$ & $25 \pm 1.0$ & $22 \pm 1.5$ \\
\hline
\end{tabular}

* Standard Drug: Benzylpenicillin

\section{CONCLUSION}

Herein, we reported the green synthesis of copper nanoparticles with the seed extract of Nelumbo nucifera which provides efficient, simple, ecological and inexpensive profitable procedures for the synthesis of metallic nanoparticles. The reduction of copper ions into copper nanoparticles was carried out with the bio-reductants present in the seed extract. These biosynthetic copper nanoparticles exhibited good to excellent antibacterial activity which revealed their potential applications in pharmaceutical and biomedical fields. Furthermore, these CuNps works well as excellent catalysts towards Huisgen $[3+2]$ cycloaddition reaction. Finally, we conclude that our experimental results encourage the researchers towards the improvement of green techniques as we used green reaction conditions for both fabrication of nanoparticles as well as the synthesis of 5-(4-Nitrophenyl)- ${ }^{1} H$-tetrazole. 
RASĀYAN J. Chem.

Vol. 13 | No. 3 |1885-1893| July - September | 2020

\section{ACKNOWLEDGEMENT}

The authors wish to thank the University of Hyderabad, Hyderabad and Sri Jayachamarajendra College of Engineering, Mysore for providing characterization, sample analysis and catalytic activity facilities. We also express our sincere thanks to Mr. C. M. Narendra Reddy, Dept. of Biotechnology, Dravidian University, Kuppam for providing anti-bacterial Studies.

\section{REFERENCES}

1. C.J. Murphy, Science. 298, 2139(2002), DOI:10.1126/science.1080007

2. N.K. Ojha, G.V. Zyryanov, A. Majee, V.N. Charushin, O.N. Chupakhin and S. Santra, Coordination Chemistry Reviews, 353, 1(2017), DOI:10.1016/j.ccr.2017.10.004

3. J.L. Elechiguerra, J.L. Burt, J.R. Morones, A.C Bragado, X. Gao, H.H. Lara and M.J. Yacaman, Journal of Nanobiotechnology,3, 6(2005), DOI:10.1186/1477-3155-3-6

4. N.A. Begum, S. Mondal, S. Basu, R.A. Laskar and D. Mandal, Colloids and Surfaces B: Biointerfaces, 71, 113(2009), DOI:10.1016/j.colsurfb.2009.01.012

5. S. Navaladian, B. Viswanathan, R.P. Viswanath and T.K. Varadarajan, Nanoscale Research Letters, 2, 44(2007), DOI:10.1007/s11671-006-9028-2

6. M. Starowicz, B. Stypula and J. Banas, Electrochemistry Communications, 8, 227(2006), DOI:10.1016/j.elecom.2005.11.018

7. K.S. Sreeram, M. Nidin and B.U. Nair, Bulletin of Materials Science, 31, 937(2008), DOI: $10.1007 / \mathrm{s} 12034-008-0149-3$

8. H. Wang, J. Xu, J. Zhu and H. Chen, Journal of Crystal Growth, 244, 88(2002), DOI:10.1016/S00220248(02)01571-3

9. H. Xie, J.-R. Wang, L.-F. Yau, Y. Liu, L. Liu, Q.-B. Han, Z. Zhao and Z.-H. Jiang, Molecules,19, 4466(2014), DOI:10.3390/molecules19044466

10. K. Kathiresan, In Proceedings of the $5^{\text {th }}$ National Conference of Indian Association of Applied Microbiologists on Emerging Trends \& Evolving Technologies in Applied Microbiology with Special Reference to Microbial Nanotechnology, Kanchipuram, India, January,11-12, 35, (2007).

11. K. Kathiresan, S. Manivannan, M.A. Nabeel and B. Dhivya, Colloids and Surfaces B: Biointerfaces, 71, 133(2009), DOI:10.1016/j.colsurfb.2009.01.016

12. A. Tripathy, A.M. Raichur, N. Chandrasekaran, T.C. Prathna and A. Mukherjee, Journal of Nanoparticle Research, 12, 237(2010), DOI:10.1007/s11051-009-9602-5

13. M. Nasrollahzadeh, S.M. Sajadi and M. Khalaj, RSC Advances, 4, 47313(2014), DOI:10.1039/C4RA08863H

14. N. Elisma, A. Labanni, Emriadi, Y. Rilda, M. Asrofi and S. Arief, Rasayan Journal of Chemistry, 12, 1752(2019), DOI:10.31788/RJC.2019.1245347

15. J. Ramyadevi, K. Jeyasubramanian, A. Marikani, G. Rajakumar and A.A. Rahuman, Materials Letters, 71, 114(2012), DOI:10.1016/j.matlet.2011.12.055

16. Y. Wei, S. Chen, B. Kowalczyk, S. Huda, T.P. Gray and B.A. Grzybowski, Journal of Physical Chemistry C, 114, 15612, DOI: $10.1021 /$ jp 1055683

17. T. Yasukawa, H. Miyamura and S. Kobayashi, Chemical Society Reviews,43, 1450(2014), DOI: 10.1039/C3CS60298B

18. M. Reddeppa, R.C.K. Reddy, Y. Paulraj and T.S. Rani. Asian Journal of Chemistry, 31, 622(2019), DOI:10.14233/ajchem.2019.22085

19. R. Othman, N.A.B. Hanifah, R. Ramya, F.A. B.M. Hatta, W.S.H.B.W. Sulaiman, M.B. Yaman and Z.M.B. Baharuddin, International Journal of Sustainable Energy and Environment Research. 3, 178(2014).

20. S. Rai, A. Wahile, K. Mukherjee, B.P. Saha and P.K. Mukherjee, Journal of Ethnopharmacology, 104, 322(2006), DOI:10.1016/j.jep.2005.09.025

21. J.-Z. Wu, Y.-B. Zheng, T.-Q. Chen, J. Yi, L.-P. Qin, K. Rahman and W.-X. Lin, Food Chemistry,105, 540(2007), DOI:10.1016/j.foodchem.2007.04.011

22. C.P. Khare, 2004, Indian Herbal Remedies: Rational Western Therapy, Ayurvedic, and Other Traditional Usage, Botany, $1^{\text {st }}$ edn. USA: Springer, 326-327, DOI:10.1007/978-3-642-18659-2 
RASĀYAN J. Chem.

Vol. 13 | No. 3 |1885-1893| July - September | 2020

23. P.K. Mukherjee, D. Mukherjee, A.K. Maji, S. Rai and H. Michael, Journal of Pharmacy and Pharmacology, 61, 407(2009), DOI:10.1211/jpp.61.04.0001

24. R.N. Butler, A.R. Katritzky, C.W. Rees and E.F.V. Scriven, Comprehensive Heterocyclic Chemistry, Pergamon, Oxford, UK, 4, p.621(1996).

25. R. J. Herr, Bioorganic \& Medicinal Chemistry, 10, 3379(2002), DOI:10.1016/S0968-0896(02)002390

26. M. Ariannezhad, D. Habibi and S. Heydari. Polyhedron, 160, 170(2019), DOI:10.1016/j.poly.2018.12.037

27. R.J. Moon, A. Martini, J. Nairn, J. Simonsen and J. Youngblood, Chemical Society Reviews,40, 3941(2011), DOI:10.1039/C0CS00108B

28. Y. Na, S. Park, S.B. Han, H. Han, S. Ko and S. Chang, Journal of American Chemical Society, 126, 250(2004), DOI:10.1021/ja038742q

29. B. Baruwati, V. Polshettiwar and R.S. Varma, Tetrahedron Letters, 50, 1215(2009), DOI:10.1016/j.tetlet.2009.01.014

30. M. Takasaki, Y Motoyama, K. Higashi, S.H Yoon, I. Mochida and H. Nagashima, Chemistry-An Asian Journal, 2, 1524(2007), DOI:10.1002/asia.200700175

31. G. Centi and S. Perathoner, Catalysis Today, 77, 287(2003), DOI:10.1016/S0920-5861(02)00374-7

32. A.R. Vartooni, M. Alizadeh and M. Bagherzadeh, Beilstein Journal of Nanotechnology, 6,2300(2015), DOI:10.3762/bjnano.6.236

33. C. Perez, M. Paul and P. Bazerque, Acta Biologiae et Medicinae Experimentalis, 15, 113(1990).

34. M. Vijayalakshmi, Rasayan Journal of Chemistry, 11, 857(2018), DOI:10.31788/RJC.2018.1123033

35. J. Panda, L. Adhikari, A. Pal, S.S. Rout, S. Pattanaik and P. Pradhan, Rasayan Journal of Chemistry, 13, 556(2020), DOI:10.31788/RJC.2020.1315477

36. I. Ahmad and A.Z. Beg, Journal of Ethnopharmacology, 74, 113(2001), DOI:10.1016/S03788741(00)00335-4

37. J.A. Creighton and D.G. Eadon, Journal of the Chemical Society, Faraday Transactions, 87, 3881(1991), DOI:10.1039/FT9918703881

38. N. Sreeju, A. Rufus and D. Philip, Journal of Molecular Liquids, 221, 1008(2016), DOI:10.1016/j.molliq.2016.06.080

39. K.M. Rajesh, B. Ajitha, Y.A.K. Reddy, Y. Suneetha, P.S. Reddy and C.W. Ahn, Advances in Natural Sciences: Nanoscience and Nanotechnology, 9, 035005(2018), DOI:10.1088/2043-6254/aad12f

40. C. Chandra and F. Khan, Journal of Radioanalytical and Nuclear Chemistry, 324, 589(2020), DOI:10.1007/s10967-020-07080-1

[RJC-5830/2020] 